\title{
Complex sternal and rib reconstruction with allogeneic material
}

\author{
Charles Miles Maliska III ${ }^{1}$, Robert Lloyd Archer $^{2}$, Sharon Kaye Tarpley ${ }^{3}$, \\ Archibald Sanford Miller III ${ }^{3}$ \\ ${ }^{1}$ Department of Surgery, University of Oklahoma College of Medicine-Tulsa, Tulsa, OK; ${ }^{2}$ Saint Francis Heart Hospital, Tulsa, OK; ${ }^{3}$ Tulsa \\ Plastic Surgery, Tulsa, OK, USA
}

\begin{abstract}
Sternal malunion, or loss, developed after a median sternotomy cannot only be difficult to manage and treat, but also may diminish one's quality-of-life drastically. The technique presented here represents a multispecialty approach in one stage for the reconstruction of an unstable thoracic cage. The procedure utilized a donated sternum and ribs. The sternum with ribs harvested from a single donor included adipose derived stromal vascular fraction (ADSVF) cells with marrow also from the same donor. Autologous muscle flaps, stabilized with acellular dermal matrix were utilized to provide a robust blood supply to the ADSVF cells and bone grafts. Acellular dermal matrix was used to construct the ribs and stabilize the plugs of stem cells and bone. These procedures, in the hands of multispecialty physicians, have led to several successful reconstructions involving complex chest wall deformities. This surgical intervention was performed in a one stage operation. This represents the first successful complete sternal transplant in a patient with return to normal activities and increased quality-of-life.
\end{abstract}

Keywords Reconstructive surgical procedures / Thoracic surgical procedures / Sternum / Adipose derived stromal vascular fraction cells / Fractures, malunited

Received: 31 Jan $2017 \bullet$ Revised: 20 Aug 2018 • Accepted: 7 Sep 2018

pISSN: 2234-6163 • elSSN: 2234-6171 • https://doi.org/10.5999/aps.2017.00122 • Arch Plast Surg 2018;45:593-597

\author{
Correspondence: \\ Charles Miles Maliska III \\ Department of Surgery, University of \\ Oklahoma College of Medicine-Tulsa, \\ 4502 E. 41st Street, Tulsa, OK 74135, \\ USA \\ Tel: +1-619-341-9106 \\ Fax: +1-972-429-4732 \\ E-mail: c.milesmaliskaiii@gmail.com
}

\section{INTRODUCTION}

The complex pathology in chest wall injuries poses a challenge for both plastic reconstructive surgeons and thoracic surgery. Indications for chest wall resection and reconstruction include neoplastic processes, radiation injury, trauma, infection and sternal dehiscence $[1,2]$. Utilizing newly developed materials and technology, new products used in many specialties will return patients to health.

\section{CASE}

We present a 62-year-old female. The patient had a history of myocardial infarction and a five-vessel bypass in 2008. She fell 3 months after, fracturing her sternum. Her health comorbidities included non-insulin dependent diabetes mellitus type II, hypertension, hyperlipidemia, hypothyroidism, 20-year pack per day tobacco abuse, and peripheral vascular disease. She underwent multiple surgical debridements, which resulted in a total loss of her sternum. The patient developed an extreme version of flail chest syndrome. She was dependent upon opioids and had been wheelchair-bound for 5 years. She described a 6-year history of debilitating sternal instability with chronic pain and inability to ambulate. Her pain medications included fentanyl transdermal patches supplemented with oral hydrocodone. Her pain was constant and at least an 8 on the pain scale. She was re-

Copyright (C) 2018 The Korean Society of Plastic and Reconstructive Surgeons

This is an Open Access article distributed under the terms of the Creative Commons Attribution Non-Commercial License (http://creativecommons.org/

licenses/by-nc/4.0/) which permits unrestricted non-commercial use, distribution, and reproduction in any medium, provided the original work is properly cited. I www.e-aps.org 
ferred for the possibility of performing a sternal stabilization procedure to decrease her pain.

For the initial planning $[3,4]$, an arteriogram, chest X-ray and a three-dimensional computed tomography (3-D CT) scan were performed (Fig. 1). A cardiothoracic surgeon was consulted for evaluation and clearance, and to assist with the procedure. The patient's thoracic cage dimensions were sent to the cadaveric data bank to seek the availability of a cadaveric sternum with ribs. After notification of the availability of a donor sternum

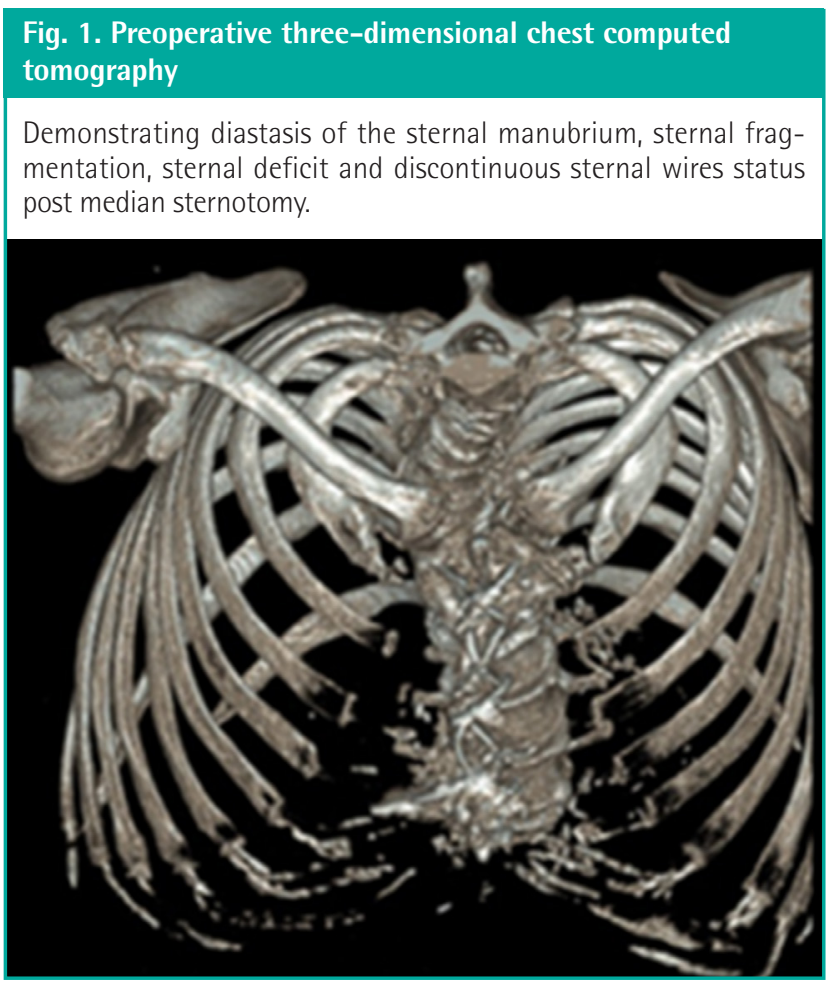

(Fig. 2A), surgery was scheduled and preceded with equipment requests including sternal plating systems, adipose derived stromal vascular fraction (ADSVF) cells (Fig. 2B) [5], and routine surgical instruments.

In accordance with the Food and Drug Administration (FDA) position on adipose tissue derived cell products, this paper complies with the definition of "minimal manipulation." Section 361 of the PHS act and dissection 351, are delineated in 21 CDF CFR 1271.10. The FDA defined and this instruction that fat that he has been harvested by liposuction is defined as "structural tissue." The components are: adipocytes and extracellular matrix. The isolation of any "nonstructural component cells" from the adipose tissue by any means is defined as "more than minimal manipulation." Examples of minimal manipulation are harvesting with liposuction cannulas, aliquoting, rinsing the material, removal of macroscopic debris, and finally anatomic freezing. The materials utilized in this procedure are harvested by suction lipectomy from cadavers utilizing standard procedures, rinsed, and has macroscopic debris separated, and then flash frozen. The materials are tested for the presence of by virus particles and communicable disease. The preserved materials have permission from the donor families to be utilized in surgery. The materials are delivered, thawed, and utilized without alteration in surgical intervention by orthopedic surgeons, neurosurgeons, podiatrist's, and plastic surgeons. The tissues utilized in this case report are ADSVF, and as such are not considered to be treated as more than "minimal manipulation [5-7]." Having met FDA standards for approval to use in commercial setting on humans, this case report and procedure does not require an Institutional Review Board approval. Preoperatively, patient edu-

Fig. 2. Preparation of cadaveric sternum and AlloStem

(A) Cadaveric sternum and (B) AlloStem. Stem cell rich bone matrix and reinforcement with acellular matrix as reconstructive biological components.
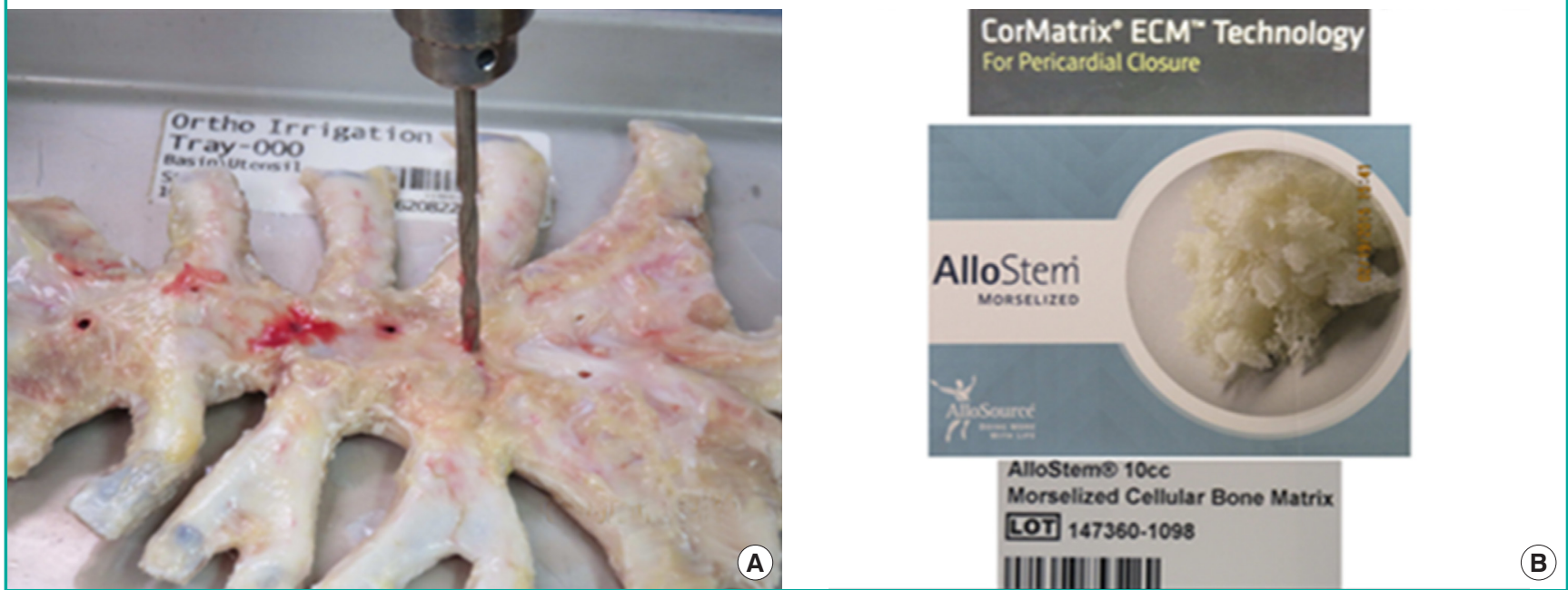
cation regarding nutrition, nicotine cessation, was begun; in addition, the risks, benefits, alternatives, potential complications and expected outcomes of the procedure were discussed in detail. Patient verbalized acknowledgement and understanding of the treatment plan, resulting in an informed decision being made to proceed. After complete education and preparation with preoperative oral antibiotics, the patient underwent this single stage complex operation.

She was placed into a supine position. A standard cardiac preparation was performed. An impregnated Ioban drape covered the entire field. The central scar was excised and the wound was debrided. A fasciocutaneous flap was elevated from midline to the right exposing the rectus muscle. The inferior epigastric artery and veins were ligated. The muscle was divided at the insertion and elevated. The right rectus sheath was sutured to the left medial contralateral rectus sheath (Fig. 3A). A $6 \times 18 \mathrm{~cm}$ acellular dermal matrix $(\mathrm{ADM})$ reinforced the closure. The pectoralis major muscles were separated from their attachments including the clavicular surface and lower rib attachments. The tendon at the humerus remained intact. Pain pump catheters were inserted transcutaneous and put under the rectus and the pectoralis muscles. Prior to placing the pectoralis in its position, the $\mathrm{ADM}$ was sutured in place over the heart and lungs creating a bridge and closing the thoracic cavity. The rectus was sutured up to the clavicles.

The ADSVF cells to be utilized were commercially prepared by the AlloSource company. The ADSVF cells were harvested from the abdominal area of the cadaveric sternal donor, were placed in suspension, and then finally passed through a cell sorter designed to separate the ADSVF cells. Once the ADSVF cells

Fig. 3. Placement of cadaveric sternum with supporting materials

(A) Rectus muscle flap: stabilization of rotated rectus muscle. (B) Cadaveric sternum: stabilization of rectus muscle with placement of sternal bone on top of rotated rectus muscle. (C) Plating of ribs and sternum: completion of plating cadaveric sternum and host ribs. (D) Stem cells \&t acellular matrix placed, pectoralis muscles advancement: plated sternum and ribs with stem cells and matrix secured into place with overlying acellular matrix advancement of pectoralis muscles overlying sternal plates and grafts.
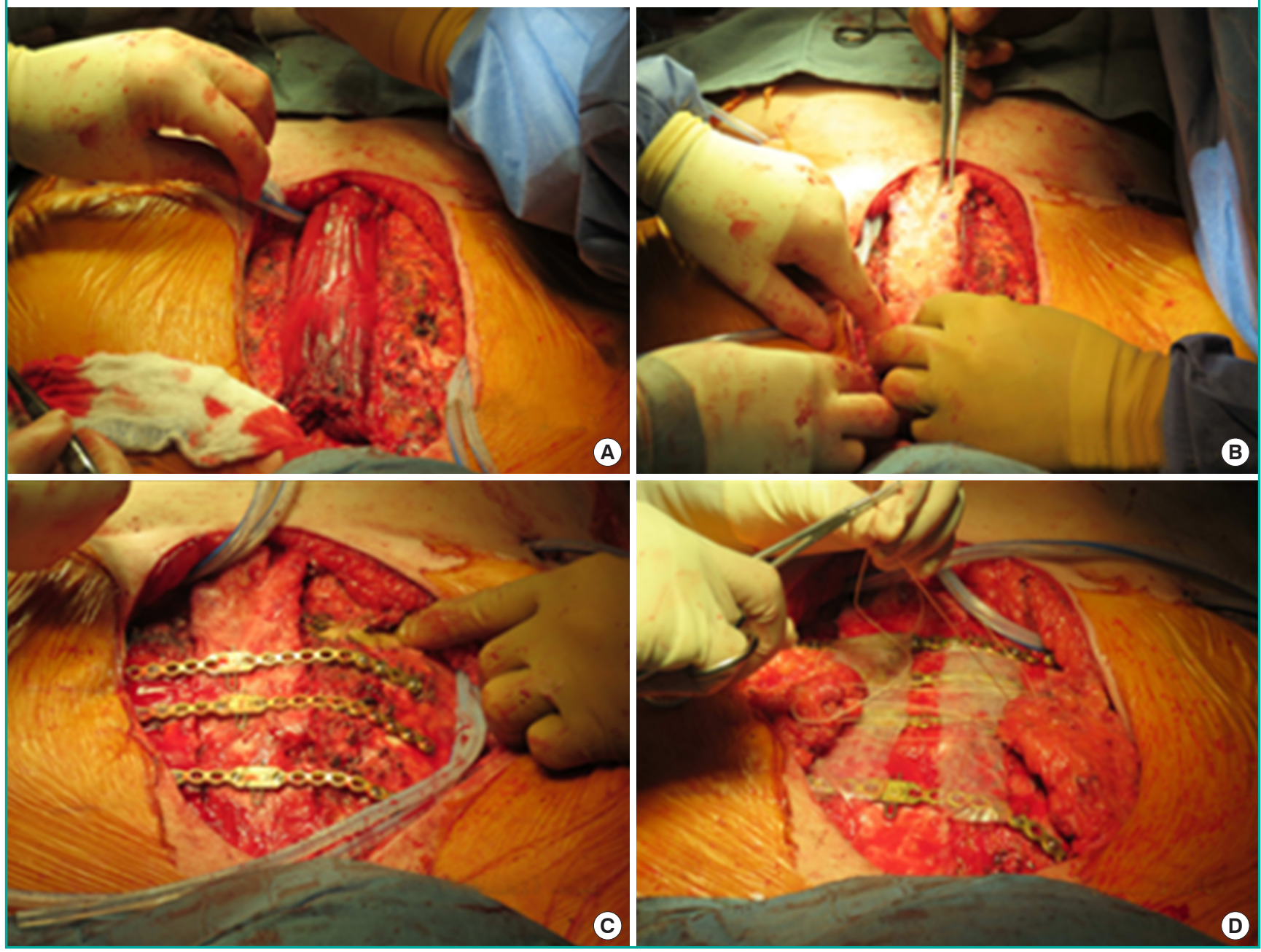
Fig. 4. Postoperative and preoperative comparison of sternum
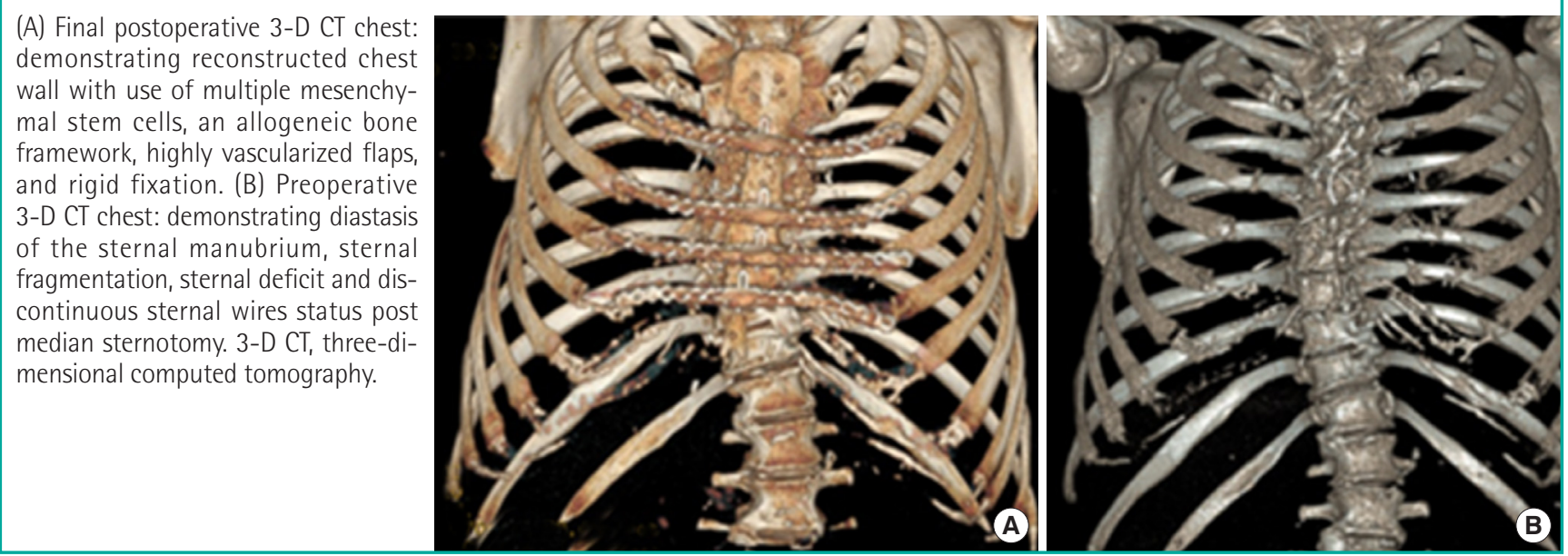

were sorted, they were frozen until ready to be used on site. On site, the ADSVF cells were thawed and mixed with a bone marrow matrix to be utilized with bony structures only.

The sternum was placed and in between each rib and clavicles and we also placed donated ADSVF cells and marrow (Fig. 3B). The fenestrations in the sternum also had ADSVF cells placed. Reconstructive sternal plates were used to stabilize the right rib to the sternum and the sternum to the left rib (Fig. 3C). ADM was placed securely on the plated sternum and ribs, and then, the pectoralis muscles were advanced and sutured over the sternum (Fig. 3D). At this point, the sternum and rib segments were sandwiched between two viable and highly vascular muscle bodies. Complete closure was performed and negative pressure wound therapy was not required. The patient was put into a binder. She was admitted to a step-down unit overnight and spent 4 days postoperatively in the hospital. She was discharged on an oral antibiotic regimen of metronidazole and ciprofloxacin. These were continued until the drains were removed, which was 3 and a half weeks postoperatively.

The patient was seen weekly for 1 month. Five months after surgery, the incision was healed well. We analyzed a new 3-D CT scan. This demonstrated a stable, healed sternum and ribs. The patient was fully ambulatory and reported zero on the pain scale. A bone scan was also performed and showed bony growth. The scan showed centripetal healing of the entire sternum. The patient had been converted from a wheelchair-bound individual dependent on narcotics to a normally ambulating person.

Her 2-year follow-up shows a patient who is living a normal life and employed. She no longer takes narcotics. She is smoking cigarettes again. She reports a normal lifestyle and is extremely happy with her postoperative life. Her final 3-D CT scan shows complete healing of her sternum and ribs with reintegration and normal alignment of her ribs and sternum (Fig. 4A) as compared to her preoperative 3-D CT scan (Fig. 4B). Her bone scan in the lateral view shows complete vascularization of the sternum itself.

\section{DISCUSSION}

When evaluating a patient for chest wall reconstruction, a thorough assessment of the defect must account for etiology, location, and understanding of the mechanics and physiology of the chest wall. Complex thoracic defects require attention to management of the pleural space, skeletal support, pulmonary compliance, and vascularized soft tissue coverage [8]. When one considers using cadaveric bone grafts, stem cells should be used to maximize reintegration. The mesenchymal multifocal stem cell is undifferentiated and has a potential for converting into multiple tissue lines. The use of these ADSVF cells derived from human adult adipose tissue is an important addition to the surgery. They process the potential to transform themselves into the characteristics of immediately surrounding tissue. This includes bone, cartilage, and muscle. This allows the enhancement of tissue growth and results in improving overall healing. This ability makes ADSVF cells desirable in reconstructive efforts in attempting to enhance the healing and growth of surrounding tissues $[9,10]$. There is controversy in the use of ADSVF cells in the presence of abnormal cells such as cancer [11]. We believe the use of ADSVF cells in this cadaveric sternal platform increased incursion of osteoblasts, neutrophils, macrophages, and fibroblasts. This defect has heretofore been designated as unrepairable. The use of allogeneic homograft shows a favorable human response and has diminished adverse host response mechanisms. The repair of the sternal loss or malunion can now be performed successfully with the use of ADSVF cells 
and cadaveric bone. The combination of these techniques with stabilizing plates and muscle flaps is vital to its success.

In summary, an innovative method is demonstrated for reconstruction after sternal loss and surgical injury. For the first time, we have successfully transplanted a complete cadaveric sternum transplant that is infused with allograft adipose derived mesenchymal stem cells with muscle flaps using plate stabilization. The principles of using multiple ADSVF cells, an allogeneic bone framework, highly vascularized flaps, and rigid fixation should now be considered in future reconstructive efforts in order to return patients to an improved quality of life.

\section{NOTES}

\section{Conflict of interest}

No potential conflict of interest relevant to this article was reported.

\section{Ethical approval}

The study was performed in accordance with the principles of the Declaration of Helsinki. Written informed consents were obtained.

\section{Patient consent}

The patient provided written informed consent for the publication and the use of her images.

\section{ORCID}

Charles Miles Maliska III https://orcid.org/0000-0001-8413-1152

\section{REFERENCES}

1. Mansour KA, Thourani VH, Losken A, et al. Chest wall resections and reconstruction: a 25-year experience. Ann Thorac Surg 2002;73:1720-5.
2. Chepla KJ, Salgado CJ, Tang CJ, et al. Late complications of chest wall reconstruction: management of painful sternal nonunion. Semin Plast Surg 2011;25:98-106.

3. Pancholy B, Raman J. Chest wall reconstruction using sternal plating in patients with complex sternal dehiscence. Ann Thorac Surg 2015;99:2228-30.

4. Kalab M, Molitor M, Kubesova B, et al. Use of allogenous bone graft and osteosynthetic stabilization in treatment of massive post-sternotomy defects. Eur J Cardiothorac Surg 2012;41:e182-4.

5. Banyard DA, Salibian AA, Widgerow AD, et al. Implications for human adipose-derived stem cells in plastic surgery. J Cell Mol Med 2015;19:21-30.

6. Bersenev A. Breaking down fat: ISCT, and IFATS position statements on stromal cells from adipose tissue [Internet]. Stem Cell Assays, c2013 [cited 2018 Sep 27]. Available from http://stemcellassays.com/2013/04/breaking-fat-isct-ifatsposition-statement/.

7. Deans RJ, Moseley AB. Mesenchymal stem cells: biology and potential clinical uses. Exp Hematol 2000;28:875-84.

8. Losken A, Thourani VH, Carlson GW, et al. A reconstructive algorithm for plastic surgery following extensive chest wall resection. Br J Plast Surg 2004;57:295-302.

9. Bryant JR, Eid R, Spann JC, et al. Chest wall reconstruction with creation of neoribs using mesenchymal cell bone allograft and porcine small intestinal submucosa. Plast Reconstr Surg 2010;126:148e-149e.

10. Wakitani S, Okabe T, Horibe S, et al. Safety of autologous bone marrow-derived mesenchymal stem cell transplantation for cartilage repair in 41 patients with 45 joints followed for up to 11 years and 5 months. J Tissue Eng Regen Med 2011;5:146-50.

11. Torsvik A, Bjerkvig R. Mesenchymal stem cell signaling in cancer progression. Cancer Treat Rev 2013;39:180-8. 